\title{
ALGUNAS REFLEXIONES ACERCA DEL PROCESO EUROPEO DE ESCASA CUANTÍA
}

\author{
SOME REFLECTIONS ABOUT THE EUROPEAN SMALL CLAIMS PROCEDURE
}

\author{
Nancy V ernengo Pellejero ${ }^{1}$
}

Fecha Recepción: 08/09/2011

Fecha Aceptación: 02/11/2011

\begin{abstract}
RESUMEN
Uno de los principales objetivos de las instituciones europeas ha sido, sin ningún género de duda, la creación de un mercado común. Sin embargo, la consecución de este objetivo requiere de la superación de algunas reservas aún existentes en los ordenamientos jurídicos de los distintos Estados miembros. Es en este punto donde se centran los trabajos de la Comisión Europea para la consecución de un espacio jurídico común, en el que se dé respuesta a las controversias surgidas a nivel transfronterizo y donde el Proceso Europeo de Escasa Cuantía del Reglamento 861/2007, del Parlamento Europeo y del Consejo, de 11 de julio de 2007, también tiene cabida; configurándose como proceso común para el enjuiciamiento de aquellas reclamaciones de inferior cuantía que provengan de los distintos estados de la Unión Europea (con excepción de Dinamarca) en las que el legislador ha buscado, ante todo, la simplificación y la agilidad en su tramitación.
\end{abstract}

Palabras clave: Procesos de escasa cuantía - espacio judicial europeo - procedimiento simplificado

\begin{abstract}
One of the main objectives of European institutions have been, doubtless, the Common Market creation. Nevertheless, the different Member States need to rise some existing exception from their own law system. European Commission is working in this same thing nowadays and it's trying to find a Common European Law Space to analyze all the European trials about different sujects; in this same place we can find the Regulation (EC) No. 861/2007, of the European Parliament and of the Council, of 11 july 2007, establishing a European Small Claims Procedure; that have been created as an easy and simple procedure for all those small claims of European States (unless Denmark).
\end{abstract}

Key words: Small Claims Procedure - European Space for Justice - Simplified Procedure

1 Becaria del Departamento de Derecho Administrativo y Derecho Procesal de la Universidad de Barcelona. Correo: nancyxxii@icab.cat 


\section{OBJETIVOS}

La iniciativa para la creación del Proceso Europeo de Escasa Cuantía surge de la disparidad de normas procesales existentes para la regulación de los procesos de escasa cuantía en cada uno de los Estados miembros. Esta disparidad normativa, unida a los dilatados plazos para la resolución de estos litigios y a los elevados costes que pueden llegar a generar en comparación con el importe de la cuantía reclamada, ha derivado en una situación no carente de cierta irracionalidad que el legislador europeo ha tratado de solventar ${ }^{2}$. Mediante el Proceso Europeo de Escasa Cuantía del Reglamento 861/2007, del Parlamento Europeo y del Consejo, de 11 de julio de 2007, se ha instaurado una suerte de proceso transfronterizo, que pretende ejercer el mismo papel que los procesos de escasa cuantía internos ${ }^{3}$; suprimiendo, al mismo tiempo, la necesidad de exequátur, un trámite judicial imperativo hasta el momento que obstaculizaba la aplicación directa de los títulos ejecutivos.

El proceso europeo de escasa cuantía no solo responde a los objetivos de simplificar y acelerar los litigios de menor cuantía en asuntos transfronterizos ${ }^{4}$, sino que también intenta reducir los costes de la justicia ${ }^{5}$. Este procedimiento resulta de aplicación a los asuntos transfronterizos en materia civil y mercantil, con independencia de la naturaleza del órgano jurisdiccional, cuando el valor de la demanda, excluidos los intereses, gastos y costas, no rebase los dos mil euros en el momento en que el órgano judicial competente reciba el formulario de demanda. Y todo ello, sin incluirse las materias fiscal, aduanera y administrativa; los casos en que el Estado incurra en responsabilidad por acciones $u$ omisiones en el ejercicio de su autoridad; y aquellos asuntos (vg. el estado civil y capacidad de las personas, obligaciones de alimentos, testamentos, procedimientos concursales, seguridad social y arbitraje) que vienen recogidos en el apartado segundo del art. 2 del propio Reglamento 861/2007.

2 Acerca de los fundamentos que dieron origen al PEEC ver, entre otros, Kramer, Xandra, The European small claims procedure. Striking the balance between simplicity and fairness in European litigation /en/ Zeitschrift für Europäisches Privatrecht, nº 2, 2008, Alemania, pp. 355-373.

3 González Cano, María Isabel, Aspectos fundamentales de la tramitación del proceso europeo de escasa cuantía, establecido en el Reglamento (CE) no 861/2007, de Parlamento Europeo y del Consejo, de 11 de julio de 2000 /en/ Revista Aranzadi Unión Europea, nº 2, 2009, Navarra, pp. 5-27.

4 Para un análisis en profundidad de la naturaleza de este proceso, ver, entre otros: Martí Martí, Joaquín, La ejecución en España del proceso europeo de escasa cuantía /en/ Diario La Ley, n 7204, 2009, Madrid, pp. 7-11; así como Loredo Colunga, Marcos, ¿Hacia un Derecho procesal europeo? Reflexiones en torno al proyecto del procedimiento europeo de escasa cuantía /en/ InDret, Revista para el análisis del derecho, no 1, 2006, Barcelona, pp. 1-24. "Disponible en World Wide Web http://www.indret.com/ pdf/325_es.pdf".

5 Vid. Arias Rodríguez, José María, Breves notas críticas sobre el proceso europeo de escasa cuantía regulado en el Reglamento (CE) 861/07 /en/ Revista del Poder Judicial, nº85, 2007, Madrid, pp. 11-34. 


\section{PROCEDIMIENTO}

Respecto al límite cuantitativo aplicable, la fijación de la cuantía máxima en 2.000 euros puede resultar irrisoria en atención al nivel económico de algunos de los Estados que aprobaron el Reglamento ${ }^{6}$. De ahí, precisamente, que no pueda descartarse que dicha cuantía, antes del 1 de enero de 2014 (fecha límite que se ha fijado para la revisión obligatoria del Reglamento), pueda verse incrementada ${ }^{7}$.

Por otra parte, la normativa europea no ha establecido mención alguna respecto a las demandas, nada infrecuentes en la práctica, cuya cuantía es indeterminada. Del tenor literal del art. 2 del Reglamento puede deducirse que todas aquellas demandas cuya cuantía no esté determinada en el momento de presentación de la demanda, habrán de quedar excluidas del ámbito de aplicación del proceso europeo de escasa cuantía ${ }^{8}$. Los problemas surgirán, como es lógico, cuando entren en juego las distintas reglas de determinación de las cuantías que han sido recogidas en los ordenamientos jurídicos de cada uno de los Estados miembros. Por ello, precisamente, lo más idóneo podría ser armonizar o unificar dichos criterios a través de la creación de unas bases mínimas para la determinación de la cuantía reclamada, evitando así que puedan producirse interpretaciones contradictorias.

6 En este sentido, para algunos Estados la cuantía máxima de 2.000€ puede resultar acertada, de acuerdo con los límites pecuniarios establecidos en su legislación interna y para sus respectivos procesos de escasa cuantía nacionales ( $\mathrm{vg}$. Alemania, donde la cuantía de lo reclamado en los procesos de escasa cuantía no ha de superar los $600 €)$. Por el contrario, sería un desacierto en otros Estados, en los cuales el importe de lo reclamado supera con creces la cuantía mínima establecida en el proceso europeo de escasa cuantía ( vg. Inglaterra y País de Gales, donde los procesos de escasa cuantía versan sobre controversias cuyo importe no ha de superar, aproximadamente, los $8.200 €$. En el caso concreto de España, la reciente reforma instaurada por la Ley 13/2009, de 3 de noviembre, de reforma de la legislación procesal para la implantación de la nueva Oficina judicial; ha introducido una modificación en el art. $250.2 .13^{\circ}$ de la Ley de Enjuiciamiento Civil; en virtud de la cual la cuantía máxima reclamable por juicio verbal pasa de 3.000 a 6.000 euros).

7 No obstante, se ha de tener en cuenta que el hecho de modificar la cuantía máxima establecida en el art. 2.1 RPEEC, no solo podría suponer una ardua tarea para el legislador, sino que resultaría excesivamente complicado, si se tiene en cuenta el nivel de vida de los Estados en los que es de aplicación el Reglamento 861/2007. A medida que se van incorporando Estados a la Unión, se amplían las fronteras de aplicación del Reglamento, a la par que se conocen los distintos procesos para la reclamación de deudas a nivel nacional y las cuantías máximas de que conocen. De ahí que sea improbable que se alcance, en un futuro próximo, un consenso común para la modificación de la cuantía y el establecimiento de un importe superior a los $2.000 €$.

8 No debe olvidarse que el proceso europeo de escasa cuantía ha sido configurado como un proceso alternativo. Siendo así, cuando no sea posible la determinación de la cuantía objeto de la reclamación, quedará abierta la vía hacia el proceso de escasa cuantía preexistente en la legislación procesal de los Estados miembros (art. 1 RPEEC). Martín Diz, Fernando, Protección procesal del crédito transfronterizo en la unión europea: propuesta de orden de embargo de activos bancarios /en/ Revista de Derecho comunitario europeo, $n^{\circ}$ 30, 2008, Madrid, pp. 381-417. 
Una de las ventajas visibles del Reglamento por el que se establece el proceso europeo de escasa cuantía reside en el hecho de que se haya optado por un sistema basado en la presentación de formularios estandarizados en las distintas etapas del procedimiento $(\mathrm{vg}$. en el momento de interposición de la demanda como reza el art. 4 del Reglamento). Esta fórmula, que ha sido heredada de otros procesos semejantes ${ }^{9}$ -sirva de ejemplo, el proceso monitorio europeo- y que encuentra también su razón de ser en el hecho de que el proceso europeo de escasa cuantía no precisa para su incoación de patrocinio técnico obligatorio, no solo agiliza la tramitación procedimental, sino que también mitiga las dificultades idiomáticas ${ }^{10}$.

Valiéndose del formulario de contestación a la demanda, el demandado tendrá la posibilidad de allanarse total o parcialmente a la demanda; oponerse a la misma, para lo cual habrá de aportar los medios de prueba que estime oportunos; o bien presentar demanda reconvencional. Asimismo, se otorga al órgano judicial un plazo máximo de catorce días, a partir de la fecha de recepción de la respuesta del demandado, para que dé traslado de esta al actor.

9 Entre ellos destaca la Ley de Enjuiciamiento Civil española, cuyo art. 437.2 contempla el uso de formularios estandarizados como una posibilidad al alcance de las partes, no como un imperativo legal. Sobre este particular, ver, entre otros, Vallespín Pérez, David, El juicio verbal /en/ Instituciones del nuevo proceso civil. Comentarios sistemáticos a la Ley 1/2000, Alonso-Cuevillas Y Sayrol, Jaime (Coord.), Economist \& Jurist, Barcelona, 2000, p. 618: "Esta demanda en impreso normalizado es tan solo una posibilidad que se le ofrece al actor, pero no una exigencia. El demandante podrá optar, por consiguiente, entre presentar la demanda en impreso normalizado, una demanda sucinta o, incluso, una demanda completa".

10 La simplificación procedimental encuentra su base en diversos textos comunitarios, que en las últimas décadas han sido el origen de los distintos procesos transfronterizos de lucha contra la morosidad. De entre todos estos textos, merece especial mención el Libro Verde sobre el Proceso monitorio europeo y las medidas para simplificar y acelerar los litigios de escasa cuantía, de la Comisión de las Comunidades Europeas (20.12.2002); COM (2002) 746. De acuerdo con su inciso 3.3.4.3: «El uso de formularios es una manera particular de estructurar la información necesaria para incoar el proceso monitorio. Puede servir para varios fines. En primer lugar, ayuda al demandante, especialmente si no está representado por abogado, facilitándole la lista completa de cuestiones que hay que abordar con el fin de presentar una petición admisible, acompañada idealmente de algunas observaciones explicativas de cada uno de los extremos. En segundo lugar, es una herramienta importante para facilitar el uso del procesamiento electrónico de datos, particularmente si se combina con la posibilidad de transmisión electrónica de la petición al órgano jurisdiccional. Además, en asuntos transfronterizos, la existencia de formularios multilingües puede contribuir perceptiblemente a la simplificación y agilización del proceso reduciendo a un mínimo las traducciones, los costes resultantes y la duración de las gestiones. Finalmente, una solicitud normalizada sería el requisito previo necesario para una resolución normalizada, que podría entonces circular libremente en la Comunidad a efectos de la ejecución». Sin obviar que este texto estaba pensado, en gran medida, para los procesos monitorios europeos, los criterios de normalización procedimental pueden ser extensibles a cualquier otro proceso europeo semejante. Sobre la influencia de los formularios estandarizados en el proceso monitorio europeo, ver Correa Delcasso, Juan Pablo, El proceso monitorio europeo, Marcial Pons, Barcelona, 2008, p. 41: "(...) gusten o no los impresos normalizados, su utilización reviste sin lugar a dudas un acierto (es incluso indispensable, nos atreveríamos a añadir) dada la disparidad de idiomas existente en la Unión Europea y la gran confusión e indefensión que una mala traducción de unos términos técnicos-como son los jurídicos-puede llegar a causar a un justiciable de cualquier país de la Comunidad". 
Del mismo modo, en lo referente a este y otros plazos, el art. 14 del Reglamento ha previsto la obligación de informar a la parte interesada sobre las consecuencias que conlleva su incumplimiento. Ello no impide, sin embargo, que el órgano judicial prorrogue excepcionalmente los plazos previstos para la subsanación de la demanda, para la contestación de la demanda principal y reconvención, y para presentar la información complementaria requerida por el tribunal. Esta prerrogativa del órgano judicial, que puede encontrar su explicación en el hecho de garantizar los derechos de las partes, parece entrar en clara contradicción con el diseño rápido y simplificado que caracteriza al proceso europeo de escasa cuantía. Ante la situación descrita cabría plantearse la opción de establecer la prórroga solo para los casos de auténtica "fuerza mayor", pero sin olvidar que el problema consistiría entonces en delimitar, en atención a la lex fori, cuando estamos en presencia de un supuesto de "fuerza mayor".

En atención a la dicción literal del Reglamento 861/2007, el formulario de demanda, la contestación y las posibles reconvenciones y descripciones de los elementos probatorios pertinentes, se presentarán en la lengua o una de las lenguas de procedimiento del órgano jurisdiccional. Sin duda, la mayor ventaja que se deriva de un sistema basado en formularios, consiste en hacer innecesaria la presencia de traductores. La única salvedad a esta regla general radica en la excepción que incorpora el inciso segundo del art. 6 del Reglamento, en el sentido de que si algún otro documento recibido por el órgano judicial estuviera redactado en una lengua distinta de la del procedimiento, dicho órgano solo podrá exigir su traducción en la medida en que la necesite para dictar sentencia. Lo desafortunado de esta redacción descansa, de una parte, en no haberse precisado por el legislador si la traducción se exigirá o no a la parte que presentó el documento; y, de otra, en que si la necesidad de esta traducción queda a criterio del órgano judicial, se hace entonces difícil explicar cómo éste puede llegar a exigir la traducción de un documento cuyo contenido y trascendencia, al no entenderlo, desconoce.

En relación a la asistencia técnica y en atención a la dicción literal del art. 10 del Reglamento, no se exigirá que las partes estén representadas por un abogado ni por cualquier otro profesional del Derecho. De lo escueto de este precepto puede concluirse que el legislador ha querido evitar el encarecimiento que para las partes supone venir representadas o asistidas en el proceso, obligatoriamente, por un profesional o experto en Derecho. Esta opción legislativa no solo pone de relieve una cierta falta de consideración hacia los derechos fundamentales de las partes ${ }^{11}$, sino

11 Sobre la protección supranacional de los derechos procesales básicos (vg. el art. 48.2 de la Carta de Derechos Fundamentales de la Unión Europea, donde se establece que "Se garantiza a todo acusado o acusada el respeto a los derechos de defensa"; y el art. 6.3 c) del Convenio Europeo de Derechos Humanos: "Todo acusado tiene, como mínimo, los siguientes derechos: (...) c) A defenderse por sí mismo o a ser asistido por un defensor de su elección y, si no tiene medios para pagarlo, poder ser asistido gratuitamente por un Abogado de oficio, cuando los intereses de la justicia lo exijan», véanse, por todos, Vallespín Pérez, David, Los nuevos retos del derecho a la tutela judicial efectiva en el proceso civil, Cims, Sabadell, 2009, pp. 17-18. 
también obviar que la postulación profesional viene amparada, máxime en un proceso transfronterizo, por la complejidad de las normas a aplicar en el proceso $^{12}$ y la necesidad de respetar el principio de igualdad de armas u oportunidades procesales. Quizás por ello, el art. 11 del Reglamento dispone que los Estados miembros deberán garantizar que las partes reciban asistencia práctica para cumplimentar los formularios. En consecuencia, en atención a una interpretación armónica de los arts. 10 y 11, resulta posible concluir que se ha reconocido, como mínimo, el derecho de las partes a gozar de aquella asistencia que sea necesaria para asegurar un mejor desarrollo del procedimiento $^{13}$.

Sobre el derecho a instar reconvención, de conformidad con la Exposición de Motivos del Reglamento 861/2007, esta ha de interpretarse de acuerdo con el contenido del art. 6, apartado 3, del Reglamento, 44/2001, del Consejo, regulador de la competencia judicial, el reconocimiento y la ejecución de resoluciones judiciales en materia civil y mercantil. Según este precepto, la posibilidad de reconvención quedará supeditada al mismo contrato o hecho que fundamente la demanda inicial.

Este mandato legal parece dejar entrever la necesidad de una cierta conexión entre ambas demandas, pero sin llegar a afirmarlo de modo expreso ${ }^{14}$. El legislador

12 Respecto a esta misma cuestión, pero trasladada al ámbito de aplicación del juicio verbal español, han adoptado idéntica postura algunos juristas: "(...) La presumible sencillez de un procedimiento por reclamaciones de cantidad baja no es un criterio por sí mismo suficiente; las consideraciones jurídicas para condenar al pago de una cantidad baja pueden ser complejas en función de los hechos y la situación jurídica y a ello cabe añadir el completo desconocimiento que el actor puede tener sobre el modo de operar los tribunales". "(...) En cambio, resulta muy sencillo remitir la posibilidad de comparecer y defenderse en juicio por sí mismo en aquellos casos en los que la Ley permite que el juicio se inicie por medio de un simple impreso (...)". Este punto de vista puede ser adoptado al tratar el proceso europeo de escasa cuantía. Juan Sánchez, Ricardo, El juicio verbal español: principales problemas para su desarrollo concentrado /en/ Carpi, Federico, Ortells, Manuel (Coords.), Oralidad y escritura en un proceso civil eficiente, Volumen II, Valencia, Publicaciones de la Universitat de València, 2008, pp. 415-424.

$13 \mathrm{Al}$ igual que sucede con la problemática en torno al cálculo de las cuantías indeterminadas que pretenden ser reclamadas mediante este proceso; el legislador también debió prever aquí un desarrollo mínimo de lo que debían interpretarse como "asistencia práctica a las partes", a modo de protocolo de actuación para los distintos Estados, en el establecimiento de una asistencia mínima que sirviera de orientación a las partes desde las oficinas del propio tribunal.

14 Sobre la necesidad de conexión entre demandas, cabe afirmar que efectivamente desconocemos si el legislador pretendía una reconvención conexa o inconexa; expresa o implícita, pues de los preceptos relativos a la reconvención nada se extrae a favor o en contra de una u otra tesis. En aras de una correcta aplicación del Reglamento, el legislador debió tener en cuenta este factor y decantarse expresamente por una u otra forma de reconvención. En relación a la legislación aplicable de los Estados miembros sobre esta cuestión y tomando como ejemplo, nuestra Ley de enjuiciamiento civil española en su art. 406.1, se establece de forma expresa la necesidad de conexión reconvencional; desterrando de forma absoluta la posibilidad de instar reconvención inconexa. Por lo tanto, y volviendo al proceso europeo de escasa cuantía, si la competencia para conocer del asunto recayera en un tribunal español, este podría exigir que se formule reconvención conexa. 
europeo tampoco se ha pronunciado sobre si la reconvención debe ser siempre expresa, o si, por el contrario, cabe instar también reconvenciones implícitas o tácitas. Este vacío legal, también apreciable en orden a los requisitos subjetivos de la reconvención, solo puede subsanarse a través de la aplicación de la legislación y jurisprudencia interna de cada Estado miembro ${ }^{15}$.

En lo relativo a la prueba, el legislador europeo ha optado por dejar en manos del órgano judicial competente la práctica probatoria. Los medios de prueba se determinarán de acuerdo con los sistemas internos de admisibilidad probatoria ${ }^{16}$; para lo cual se deberán tener en cuenta factores como la economía procesal, la pertinencia, licitud y utilidad de la misma. Del mismo modo, se deja entrever que el legislador ha optado por un sistema de prueba libre, siendo competencia del juzgador determinar los medios de prueba y los parámetros en que deberá tener lugar su práctica ${ }^{17}$. En atención al art. 9 del Reglamento, presidido por un claro antiformalismo probatorio, será admisible la obtención de pruebas a través de conversaciones telefónicas, de-

15 Por lo tanto, si la resolución del litigio dependiera de un tribunal español (art. 438.1 LEC para el juicio verbal y 406 LEC para el juicio ordinario), se exigirá conexión entre los elementos identificadores de las pretensiones (sujetos, causa de pedir y petitum) en aras de evitar la disparidad entre los hechos que sustentan la demanda y la propia reconvención. Por otra parte, y atendiendo a la forma de la reconvención, esta debería formularse de forma expresa o explícita, evitando así la posible vulneración de principios como el de defensa, audiencia y contradicción; tal y como venía sucediendo con la antigua Ley de enjuiciamiento civil española de 1881. Esta cuestión no carece de cierta polémica de acuerdo con algunos autores, pues entienden que con cada remisión que el Reglamento 861/2007 hace a la legislación estatal, se da un paso atrás en la creación del espacio europeo de seguridad y justicia. Sobre esta cuestión ver, entre otros, Senés Motilla, M. Carmen, El proceso europeo de escasa cuantía: primer paso hacia la armonización del proceso civil /en/ Revista General de Derecho Procesal, n 16, 2008, Madrid, p. 1-26. "disponible en http://www.iustel.com"

16 Forner Delaygua, Joaquim, La prueba de los hechos en el proceso: aspectos de ley aplicable, Bosch, Barcelona, 2005. pp. 195 y 196: "En consecuencia en DIPr del carácter netamente procesal de estos medios de prueba ha de ser que, sin perjuicio de la admisibilidad en sí del medio, tanto su eficacia como su valoración hayan de ser determinados por la lex fori".

17 Tomando como referente la regulación contenida en la Ley de enjuiciamiento civil española vigente, las reglas legales de valoración están destinadas, casi de forma exclusiva, a la prueba documental; mientras que para los demás medios de prueba se ha optado por el sistema de libre valoración (o reglas de la sana crítica). Con la única excepción de la prueba referida al reconocimiento por la propia parte de los hechos en los que hubiera intervenido personalmente y que operen en su contra una vez fijados como ciertos (art. 316.1 LEC); como agudamente han observado, entre otros, Abel Lluch, Xavier, Picó I Junoy, Joan, (Dirs.). Aspectos problemáticos en la valoración de la prueba civil, Bosch Editor, Barcelona, 2008; Jiménez Conde, Fernando, La apreciación de la prueba legal y su impugnación, Salamanca, Universidad de Salamanca, Publicaciones del Departamento de Derecho Procesal, 1978; Abel Lluch, Xavier, Picó I Junoy, Joan, (Coords.), Aspectos prácticos de la prueba civil, J. M. Bosch Editor, BarceIona, 2006; Vázquez Sotelo, José Luis, Presunción de inocencia del imputado e íntima convicción del tribunal, Bosch, Barcelona, 1984. p. 480 y 481 y Vallespín Pérez, David, La "reinterpretación constitucional" de la apreciación en conciencia de la LECrim española, /en/ Revista Chilena de Derecho y Ciencia Política, Vol. 3, núm. 1, año 2, 2011, p. 37-47. 
claraciones escritas de testigos, videoconferencias, audioconferencias y conferencias electrónicas ${ }^{18}$.

La posibilidad de practicar diligencias finales en el marco del proceso europeo de escasa cuantía podría llegar a interpretarse como un factor en contra de la naturaleza rápida y ágil de este procedimiento. No obstante, si tenemos presente, de una parte, que la exclusión de las diligencias finales podría llevar al juzgador, en último término, a dictar sentencias injustas a sabiendas; de otra, que el art. 9 del Reglamento tampoco incorpora su prohibición expresa; y, finalmente, que la regulación del proceso europeo de escasa cuantía no debe construirse a espaldas del obligado respeto del modelo de juicio justo ${ }^{19}$, resulta posible concluir que la adopción de dichas diligencias finales también debería tener cabida en los asuntos transfronterizos de escasa cuantía.

Respecto a la conclusión del proceso, el órgano judicial que esté conociendo del asunto deberá dictar su sentencia en un plazo máximo de treinta días tras la cele-

18 La posibilidad de celebrar la vista por videoconferencia o mediante cualquier otro medio de telecomunicación, podría considerarse otro gran acierto por parte del legislador, pues no hemos de olvidar que el litigio rebasa las fronteras de un Estado y el hecho de obligar a una de las partes a trasladarse supone una gran carga en su contra. Sin embargo, el legislador reconoce también la posibilidad de que la Administración de Justicia de los Estados miembros no tengan implantados aún estos sistemas de telecomunicación; por lo que el beneficio que supondría una audiencia a distancia, se tornaría en gravamen, cuando se vieran obligados a trasladarse hasta la sede del tribunal extranjero competente. En cualquier caso, la iniciativa de celebrar la vista utilizando estos medios cuando se disponga de ellos, no dependerá de la voluntad de las partes, sino única y exclusivamente del tribunal; pues la negativa de una de las partes a celebrar la vista mediante estos mecanismos podría suponer su intención de obligar a la otra parte a desplazarse a otro Estado o designar un representante.

19 Esta misma cuestión ha sido mencionada por la doctrina española respecto al juicio verbal y la interpretación de la normativa procesal española de acuerdo con el art. 24 CE; como tan agudamente han señalado, Ortego Pérez, Francisco, Diligencias finales en el juicio verbal. La antítesis entre el principio de concentración que preside este juicio y el derecho constitucional a la prueba /en/ Justicia: Revista de Derecho Procesal, n 3-4, 2007, Madrid, p. 219: "El tenor literal del art. 447 LEC parece descartar la práctica de tales diligencias en el juicio verbal, pero, en contrapartida, la jurisprudencia del Tribunal Constitucional respecto al derecho a la prueba establece que no es posible subordinar la vigencia de tal derecho fundamental a otro tipo de intereses tales como los de economía procesal o rapidez de los juicios (STC 10/2000, de 17 de enero)"; Vallespín Pérez, David, Diligencias finales en el juicio verbal (arts. 435 y 436 LEC) /en/ Justicia: Revista de Derecho procesal, n 3-4, 2007, Madrid, p. 234: "(...) no admitir las diligencias finales en el juicio verbal (cuya prohibición expresa tampoco ha sido prevista por nuestro legislador) podría provocar importantes consecuencias no ajustadas al obligado respeto del modelo constitucional de juicio justo o proceso con todas las garantías del art. 24.2 CE". Al mismo tiempo, el Código Procesal Civil Modelo para Iberoamérica también lo incluye en su articulado bajo la antigua rúbrica procesal española de "Diligencias para mejor proveer"; configurándose como una dispensa del Tribunal que esté conociendo del asunto, siempre que su práctica esté suficientemente motivada por el propio Tribunal y sea indispensable al juzgador para poder dictar la posterior sentencia. 
bración de la vista oral o bien tras la recepción de toda la documentación necesaria. La sentencia, que deberá ser documentada por escrito, aunque se pronuncie en la vista de forma oral, se notificará debidamente a las partes.

La sentencia será, sin perjuicio del posible recurso al que pueda verse sometida y sin necesidad de prestación de caución o fianza alguna, ejecutiva. El art. 17 del Reglamento reconoce el derecho de las partes a recurrir esta sentencia. Ahora bien, al no haberse incluido una regla uniforme en el Reglamento relativa a la posibilidad de recurrir la sentencia ${ }^{20}$, la oportunidad de interponer recurso dependerá, una vez más, de la regulación que se haya hecho de esta cuestión en el ordenamiento jurídico del Estado que esté conociendo del litigio ${ }^{21}$.

$20 \mathrm{Al}$ omitir un pronunciamiento expreso sobre esta cuestión, el legislador ha dejado entrever su intención de apostar por el principio de proporcionalidad. Desde esta perspectiva se omitiría el derecho al recurso en aras de una rápida resolución de los litigios transfronterizos. Esta cuestión ha sido objeto de numerosas críticas por parte de algunos autores, para los cuales resulta desacertado que la apelación haya sido relevada a un asunto sobre el que ha de decidir cada Estado de forma independiente, a modo de derecho de configuración legal establecido por el legislador ordinario; olvidando que nos hallamos ante un derecho fundamental. Sobre la consideración del recurso en el proceso civil como garantía procesal básica, véanse, por todas, las reflexiones de Vallespín Pérez, David, El modelo constitucional de juicio justo en el ámbito del proceso civil: conexión entre el derecho a la tutela judicial efectiva y el derecho a un proceso con todas las garantías. Atelier, Barcelona, 2002, pp. 141 y ss. en relación al art. 24.2 de la Constitución española sobre el "derecho a un proceso con todas las garantías"; así como Saavedra Gallo, Pablo (Coord.), Sistema de garantías procesales, Dijusa, Madrid, 2008.

21 Nuevamente por aplicación supletoria del art. 19 RPEEC, en el caso concreto de nuestro ordenamiento procesal, cabe la posibilidad de plantear recurso de apelación en aplicación de lo dispuesto en la Ley de Enjuiciamiento Civil para el juicio verbal. Para ello se prevé que la parte interesada presente su escrito de preparación del recurso, en un plazo máximo de cinco días desde que le fue notificada; ante el mismo tribunal que dictó la sentencia. Una vez admitido a trámite el recurso, el tribunal le otorgará un plazo de veinte días para que exponga por escrito las razones en las que fundamenta el recurso, la petición que formula a la Audiencia provincial y la solicitud para la práctica de las pruebas que considere oportunas. Tras la recepción de los autos en la Audiencia provincial, se procederá al señalamiento del día y la hora para la votación y el fallo del recurso, dictándose sentencia a continuación; excepto si se celebra vista. Por otra parte, es necesario puntualizar que el Proyecto de Ley de Medidas de Agilización Procesal que afecta, entre otras, a la Ley de Enjuiciamiento Civil, introduce importantes reformas en materia de recursos. En concreto, dispone la supresión del recurso del recurso de apelación para los juicios verbales cuya cuantía no supere los 6.000 euros. Con ello el legislador pretende impedir el uso ilimitado y en ocasiones excesivo de instancias judiciales, al mismo tiempo que pretende evitar las dilaciones innecesarias que se producen en algunos procesos. Sin embargo, el legislador parece obviar que limitar un proceso, con independencia de la cuantía de lo reclamado, a un primer y único grado, y sin un control judicial posterior, provoca la firmeza de la sentencia dictada en primera instancia. Las ansias del legislador por alcanzar un enjuiciamiento simplificado y ágil en aquellos procesos cuya cuantía sea mínima no justifica la supresión de aquellas garantías de derecho natural que son el fundamento del modelo constitucional de juicio justo del art. 24 de la Constitución. De este modo, el recurso es considerado una garantía procesal más cuya naturaleza elemental forma parte de la conciencia jurídica de la sociedad en general y responde al anhelo de justicia de todo ciudadano (una postura que defendí en la comunicación presentada en el IV Congreso Gallego y I Congreso Internacional de Derecho Procesal (A Coruña - España, 1 y 2 de junio de 2011), bajo el título "Algunas reflexiones acerca del tratamiento del derecho a los recursos en el Proyecto de Ley de Medidas de Agilización Procesal"). 
El legislador europeo también ha contemplado, en el art. 18 del Reglamento, la revisión de la sentencia firme dictada en el proceso europeo de escasa cuantía ${ }^{22}$. A pesar de esta denominación -revisión- lo cierto es que en realidad estamos más bien en presencia de un tratamiento legal de la audiencia al litigante rebelde ${ }^{23}$.

Finalmente, el art. 20 del Reglamento recoge el mandato de que cualquier sentencia o auto despachando la ejecución que se haya dictado en un Estado miembro en el ámbito de un proceso europeo de escasa cuantía, debe reconocerse y ejecutarse en otro Estado miembro, sin que pueda mediar oposición alguna por parte de ninguno de los Estados miembros ${ }^{24}$ y sin que sea preceptiva una declaración de ejecutabilidad previa. De esta forma, la resolución dictada será directamente ejecutiva y no precisará de constitución de fianza o garantía, aunque la parte perjudicada haya decidido recurrirla. El exequatur se hace así del todo innecesario para todas aquellas resoluciones dictadas en el proceso europeo de escasa cuantía ${ }^{25}$.

22 Esta previsión opera a imagen y semejanza de los arts. 19 del Reglamento (CE) 805/2004, relativo a la revisión dentro del título ejecutivo europeo para créditos no impugnados; y 20 del Reglamento (CE) 1896/2006, del Parlamento Europeo y del Consejo de 12 de diciembre de 2006, por el que se establece un proceso monitorio europeo

23 Sobre la cuestión relativa a la audiencia al litigante rebelde en la Ley de enjuiciamiento civil española, véanse, entre otros, Borrás Rodríguez, Alegría, La sentencia dictada en rebeldía: exequatur en el Convenio de Bruselas /en/ Revista de Instituciones Europeas, nº 1, 1991, Madrid, pp. 39-60; Magro Servet, Vicente, Posibilidades procesales del demandado una vez declarada la rebeldía /en/ Práctica de Tribunales. Revista de Derecho Civil y Mercantil, nº 47, 2008, Madrid, pp. 29-34; Martí Martí, Joaquín, Análisis del criterio del TC y TS en cuanto al uso de la comunicación edictal. Supuestos en que se puede recurrir a esa vía. Agotamiento de todas las vías de localización del demandado (arts. 155 y 156 LEC) / en/ Práctica de Tribunales. Revista de Derecho Civil y Mercantil, nº 47, 2008, Madrid, pp. 6-13; Samanes Ara, Carmen, Los actos procesales de comunicación y la declaración de rebeldía en el Proyecto de Ley de Enjuiciamiento Civil, Tribunales de Justicia, nº 2, 1999, Madrid, pp. 93-102; Vergé Grau, Joan, La rebeldía en el proceso civil, Editorial Bosch, Barcelona, 1989. Sobre la revisión de la sentencia firme en el proceso civil, véase, por todos: Vallespín Pérez, David, La revisión de la sentencia firme en el proceso civil, Atelier, Barcelona, 2002.

24 En este punto, el Reglamento 861/2007, introduce un elemento de simplificación necesario en el contexto del Espacio Judicial Europeo. Del mismo modo, también ha sido reconocido como necesario en el Capítulo IV del Código Procesal Civil Modelo para Iberoamérica, en el que se otorga efectos imperativos, probatorios y fuerza ejecutoria, a las sentencias extranjeras; sin que proceda su revisión sobre el fondo del asunto por parte del ordenamiento jurídico receptor de la misma.

25 En el bien entendido que el exequatur ha supuesto una exigencia necesaria desde hace décadas, siendo paulatinamente eliminado tras la entrada en vigor de distintos Reglamentos de aplicación en la Comunidad Europea; como es el caso del Reglamento 861/2007, sobre el Proceso Europeo de escasa cuantía. Sobre la ejecución de resoluciones extranjeras en el ordenamiento jurídico español y la supresión del exequatur ver, entre otros, Adroher Biosca, Salomé, Campuzano Díaz, Beatriz (Coords.), Hacia la supresión del exequatur en el espacio judicial europeo: el título ejecutivo europeo, Universidad de Sevilla, Secretariado de Publicaciones, Sevilla, 2007; Beaumont, Paul, Johnston, Emma, Abolition of the exequatur in Brusels I: Is a public policy defence necessary for the protection of human rights? /en/ IPRax: Praxis des Internationalen Privat-und Verfahrens-rechts, vol. 30, nº 2, 2010, Alemania, pp. $105-$ 110; Cabezudo Bajo, María José, La aprobación de un procedimiento monitorio europeo (en el marco 


\section{CONCLUSIONES}

El Proceso Europeo de Escasa Cuantía ha sido creado con la finalidad de abaratar costes y agilizar el procedimiento en relación a todos aquellos procesos de naturaleza transfronteriza en los que la cuantía de lo reclamado es mínima. Sin embargo, y a pesar de los esfuerzos del legislador europeo, continúan existiendo factores en contra de esta agilización procesal y que son objeto de un encarnizado debate por parte de los juristas.

El hecho de que existan algunas lagunas legales en el articulado del Reglamento 861/2007, del Parlamento y del Consejo, de 11 de julio de 2007, y que por este motivo debamos remitirnos constantemente a la normativa interna de los Estados miembro, solo añade dificultades a un proceso que debería responder a un modelo simplificado y sin dilaciones innecesarias.

Resulta un acierto que la regulación de este procedimiento incluya elementos tan importantes como la innecesaria presencia del exequatur o la utilización de formularios estandarizados en las distintas fases del procedimiento. Pero a la vez resulta contradictorio que el legislador haya optado por introducir en el articulado factores tan poco clarificadores como la confusa regulación del derecho a recurrir la sentencia del art. 17 del Reglamento 861/2007, o la ambigua redacción del art. 6.3, donde se reconoce el derecho a instar reconvención.

Para evitar interpretaciones contradictorias y confusas debería haberse optado por unificar criterios, mediante la redacción de unas bases mínimas y comunes para todos los Estados miembros, en las que se reflejaran todos aquellos elementos escasamente regulados y que precisan de mayor detalle.

Del mismo modo, no debe olvidarse que la regulación contenida en este Reglamento 861/2007 debe respetar las garantías básicas del proceso, consagradas en el art. 6 del Convenio Europeo de Derechos Humanos. De esta forma, toda interpretación o modificación posterior del articulado del Reglamento regulador del Proceso Europeo de Escasa Cuantía, deberá responder al contenido de este precepto, respetando las garantías procesales incluidas en el mismo. Solo así puede garantizarse el

\footnotetext{
de la progresiva supresión del exequatur y la armonización del Derecho procesal civil en la UE) /en/ El Tribunal Supremo, su doctrina legal y el recurso de casación, Gimeno Sendra, Vicente (Dir.). Iustel, Madrid, 2007, pp. 669-694; Garcimartín Alférez, Francisco; Prieto Jiménez, María Jesús, La supresión del exequatur en Europa: el título ejecutivo europeo /en/ La Ley, vol. V, 2004, pp. 1619-1629; Garberí Llobregat, José, El proceso de ejecución forzosa en la nueva Ley de enjuiciamiento civil. Thomson Civitas, Navarra, 2007; Schlosser, Peter, The abolition of exequatur proceedings including public policy review? /en/ IPRax: Praxis des Internationalen Privat-und Verfahrens-rechts, vol. 30, $n^{\circ} 2$, 2010, Alemania, pp.101-104;
} 
respeto de los derechos fundamentales de las partes litigantes, a la par que se alcanza el objetivo básico que ha dado lugar a la creación de este proceso. 


\section{Bibliografía}

Abel Lluch, Xavier, Pıcó I Junor, Joan (Coords.), Aspectos prácticos de la prueba civil. J. M. Bosch Editor, Barcelona, 2006.

Adroher Biosca, Salomé, Campuzano Díaz, Beatriz (Coords.). Hacia la supresión del exequatur en el espacio judicial europeo: el título ejecutivo europeo, Secretariado de Publicaciones de la Universidad de Sevilla, Sevilla, 2006.

Arias Rodríguez, José Manuel, Breves notas críticas sobre el proceso europeo de escasa cuantía regulado en el Reglamento (CE) 861/07 /en/ Revista del Poder Judicial, n 85, 2007, España.

Beaumont, Paul, Johnston, Emma, Abolition of the exequatur in Brusels I: Is a public policy defence necessary fort he protection of human rights? /en/ IPRax: Praxis des Internationalen Privat-und Verfahrens-rechts, vol. 30, n 2, 2010, Alemania.

Borrás Rodríguez, Alegría, La sentencia dictada en rebeldía: exequatur en el Convenio de Bruselas /en/ Revista de Instituciones Europeas, nº 1, 1991, España.

Cabezudo Bajo, María José, La aprobación de un procedimiento monitorio europeo (en el marco de la progresiva supresión del exequatur y la armonización del derecho procesal civil en la UE) /en/ El Tribunal Supremo, su doctrina legal y el recurso de casación. Gimeno Sendra, Vicente (Dir.). lustel, Madrid, 2007.

Correa Delcaso, Juan Pablo, El proceso monitorio europeo, Marcial Pons, Barcelona, 2008.

Forner Delaygua, Joaquín J, La prueba de los hechos en el proceso: aspectos de ley aplicable, Bosch, Barcelona, 2005.

Garcimartín Alférez, Francisco, Prieto Jiménez, María Jesús, La supresión del exequatur en Europa: el título ejecutivo europeo /en/ La Ley, Vol. V, 2004, España.

Garberí Llobregat, José, El proceso de ejecución forzosa en la nueva Ley de enjuiciamiento civil, Thomson Civitas, Navarra, 2007.

González Cano, María Isabel, Aspectos fundamentales de la tramitación del proceso europeo de escasa cuantía, establecido en el Reglamento (CE) n 861/2007, del Parlamento Europeo y del Consejo, de 11 de julio de 2007 /en/ Revista Aranzadi Unión Europea, n 2, 2009. 
JimÉnEZ CONDE, Fernando, La apreciación de la prueba legal y su impugnación, Universidad de Salamanca, Publicaciones del Departamento de Derecho procesal, Salamanca, 1978.

Juan Sánchez, Ricardo, El juicio verbal español: Principales problemas para su desarrollo concentrado /en/ Oralidad y escritura en un proceso civil eficiente. Vol. II. Carpi, Federico, Ortells, Manuel, Publicaciones de la Universitat de València, 2008, España.

Kramer, Xandra E, The European small claims procedure: Striking the balance between simplicity and fairness in European litigation /en/ Zeitschrift für Europäisches Privatrecht (ZEuP), n 2, 2008, Alemania.

Loredo Colunga, Marcos. ¿Hacia un derecho procesal europeo? Reflexiones en torno al proyecto de procedimiento europeo de escasa cuantía /en/ InDret. Revista para el análisis del Derecho, $\mathrm{n}^{\circ}$ 1, 2006, España [on line], Disponible en World Wide Web: http://www.indret.com/pdf/325_es.pdf).

Magro Servet, Vicente, Posibilidades procesales del demandado una vez declarada la rebeldía /en/ Práctica de Tribunales. Revista de Derecho civil y mercantil, $n^{\circ} 47$, 2008, España.

Martí Martí, Joaquín, Análisis del criterio del TC y TS en cuanto al uso de la comunicación edictal. Supuestos en que se puede recurrir a esa vía. Agotamiento de todas las vías de localización del demandado (arts. 155 y 156 LEC) /en/ Práctica de Tribunales, Revista de Derecho Civil y Mercantil, no 47, 2008, España, p. 6-13.

Martí Martí, Joaquín, La ejecución en España del Proceso Europeo de Escasa Cuantía /en/ Diario La Ley, nº 7204, 2009, España.

Martín Diz, Fernando, Protección procesal del crédito transfronterizo en la Unión Europea: propuesta de orden de embargo de activos bancarios /en/ Revista de Derecho comunitario europeo, $n^{\circ} 30,2008$, España.

Ortego Pérez, Francisco, Diligencias finales en el juicio verbal. La antítesis entre el principio de concentración que preside este juicio y el derecho constitucional a la prueba /en/ Justicia: Revista de Derecho procesal, nº 3-4, 2007, España.

Saavedra Gallo, Pablo (Coord.), Sistema de garantías procesales, Dijusa, Madrid, 2008

Samanes Ara, Carmen, Los actos procesales de comunicación y la declaración de rebeldía en el Proyecto de Ley de Enjuiciamiento Civil /en/ Tribunales de Justicia, $n^{\circ} 2,1999$, España. 
SChlosser, Peter, The abolition of exequatur proceedings including public policy review? /en/ IPRax: Praxis des Internationalen Privat-und Verfahrens-rechts, vol. 30, $\mathrm{n}^{\circ} 2$, 2010, Alemania.

Senés Montilla, M. Carmen, El proceso europeo de escasa cuantía: primer paso hacia la armonización del proceso civil /en/ Revista General de Derecho Procesal, $\mathrm{n}^{\circ}$ 16, 2008, España. [on line] Disponible en World Wide Web: http://www.iustel.com"

Vallespín Pérez, David, El juicio verbal /en/ Instituciones del nuevo proceso civil. Comentarios sistemáticos a la Ley 1/2000, Volumen II. Alonso-Cuevillas y Sayrol, Jaime (Coord.), Economist \& Jurist, Barcelona, 2000.

Vallespín Pérez, David, El modelo constitucional de juicio justo en el ámbito del proceso civil: conexión entre el derecho a la tutela judicial efectiva y el derecho a un proceso con todas las garantías, Atelier, Barcelona, 2002.

Vallespín Pérez, David, La revisión de la sentencia firme en el proceso civil, Atelier, Barcelona, 2002.

Vallespín Pérez, David, Diligencias finales en el juicio verbal (arts. 435 y 436 LEC) /en/ Justicia: Revista de Derecho Procesal, n³ 3-4, 2007, España.

Vallespín Pérez, David, Los nuevos retos del derecho a la tutela judicial efectiva en el proceso civil, Cims, Sabadell, 2009.

Vallespín PéRez, David, La «reinterpretación constitucional» de la apreciación en conciencia de la LECrim española. Revista Chilena de Derecho y Ciencia Política, Vol. 3, núm. 1, año 2, 2011, Chile.

VÁzquez Sotelo, José Luis, Presunción de inocencia del imputado e íntima convicción del tribunal, Bosch, Barcelona, 1984.

Vergé Grau, Joan, La rebeldía en el proceso civil, Bosch, Barcelona, 1989. 